\title{
Factors influencing the quality of preconception healthcare in China: applying a preconceptional instrument to assess healthcare needs
}

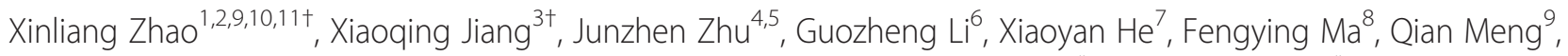
Qinying Cao ${ }^{5}$, Yucui Meng ${ }^{5}$, Christopher Howson ${ }^{10}$, Nanbert Zhong ${ }^{2,9,10,11,12,13^{*}}$ and Yaping Tian ${ }^{1 *}$

\begin{abstract}
Background: Preconception care is defined as the promotion of the health and well-being of a woman and her partner before pregnancy. Improving preconception health can result in improved reproductive health outcomes. China has issued latest version official guideline for preconception care in 2011. The objective of this cross-sectional study is to determine whether there is a variation in the quality of preconception healthcare services in distinct eastern and northern populations of China, and what factors are associated with such variation.

Methods: A cross-sectional survey using our previously developed preconception instrument was conducted. Women at reproductive age planning for pregnancy were surveyed along with their partners at hospitals during their pre-pregnancy health examination. Data collected include general health/life profiles, pregnancy history, alcohol/tobacco/drug exposures, immunizations, micronutrient supplements and the demands in preconception care. After quality assessment, statistical analysis were applied to evaluate the variations in preconception factors between people from Hebei and Jiangsu Provinces.

Results: 3202 women of reproductive age in from eastern province, Jiangsu, and in a northern province, Hebei, participated this study. 2806 of them and their partners have completed the questionnaire, at a rate of 87.6\%, 1011 were from Jiangsu and 1795 were from Hebei. Statistical significance was obtained for maternal age $(P<0.001)$, body mass index ( $u=13.590, P<0.001)$, education $\left(X^{2}=916.33, P<0.001\right)$, occupation $\left(X^{2}=901.78, P<0.001\right)$, health status/common disease, immunization status, and need for preconception care.

Conclusions: For a country as large as China, the centralized guideline for standardized preconception healthcare does have a very crucial positive role in reproductive healthcare, but it may not be suited for all populations. Regional authorities should consider the demographics and healthcare needs of the local population and modify the centralized guideline accordingly, as well as provide a better education and professional services for the public, to improve the quality of preconception services at both the regional and the national level.
\end{abstract}

Keywords: Preconception healthcare, Maternal health, Survey, China

\footnotetext{
*Correspondence: nanbert.zhong@opwdd.ny.gov; tianyp@301hospital.com.cn

'Equal contributors

${ }^{2}$ Peking University Center of Medical Genetics, Beijing, China

'Chinese PLA General Hospital/Medical School of Chinese PLA, Beijing, China

Full list of author information is available at the end of the article
} 


\section{Background}

Preconception care is defined as the promotion of the health and well-being of a woman and her partner before pregnancy [1]. Improving preconception health can result in improved reproductive health outcomes, with the potential for reducing societal costs as well [2]. Preconception care aims to promote the health of women of reproductive age before conception and thereby improve pregnancy-related outcomes [3]. Screening couples who intend to conceive should provide accurate information about their health state and cover a broad range of topics, including general lifestyle, nutrition, tobacco and alcohol use, obstetric and medical history, and genetic conditions in either parent or family.

Since 1987, several reviews have analyzed the evidence from, and documented the effectiveness of, specific preconception interventions [2,3]. The systematic review in 2002 by Korenbrot et al. of 21 research trials published during the 1990s strengthened the evidence base for preconception care in particular areas [4]. The United States Centers for Disease Control and Prevention published recommendations to improve preconception health and health care in 2006 [4]. Afterwards, Netherlands and Canada issued their own national recommendations or guidelines for preconception care [5,6]. 2012 World Health Organization issued a report and packages to strengthen the preconception care in order to reduce maternal and childhood mortality and morbidity [7].

Pre-marriage and preconception healthcare services have been provided by the Chinese government since 1980, and a nationwide maternal healthcare network is well established. The preconceptional healthcare service package has been upgraded many times. An official guideline for preconception healthcare was developed many years ago, and its latest version was released in 2011 by the Chinese Medical Association [8]. The importance of preconception healthcare has long been established, and various studies have emphasized its benefits in China [9-11]. However, detailed assessment of the needs for preconception health care, especially when comparing economically developed south China to still-developing north China, has seldom been conducted. As a large country with the highest population in the world, China has numerous geographical features widely distributed throughout the territory, and its economic statuses and life styles vary between regions, as do the general health indicators $[8,12]$; the country is also experiencing shortages and unbalanced distribution of health care services [13]. Therefore, the current maternal health care system must be assessed to maximize the effect of preconception services, understand the basic needs of couples, and design a strategy that best fits the preconceptional needs.

We conducted this study to evaluate the variation of risk factors for adverse pregnancy outcome, intentions, and needs for preconception services between the eastern and northern regions in China and to discuss the best strategy for strengthening preconceptional health care to meet the increased needs.

\section{Methods \\ Participants}

Two distant provinces, Jiangsu and Hebei, were selected because of the differences in their environmental, geographical, and economical features and in their residents' lifestyles. Jiangsu province is in the plains region of east China and is known by its characteristic urban lifestyle and its middle-class to wealthy living standard, whereas Hebei is a mountainous province located in north China and is known for less developed rural life and lower standard of living; both provinces are coastal. This project has been reviewed and approved by the Institutional Ethics Committee in both Jiangsu Provincial Center for Maternal and Children's Health and Hebei Provincial People's Hospital.

A questionnaire we developed earlier as a preconceptional instrument was based on the common risk factors for pregnancy complications and couples' needs. The survey was conducted in Jiangsu and Hebei provinces independently. Three geographically separated hospitals were selected as the data collection fields for each province. The survey period was from March 2010 to May 2012.

Couples who intended to conceive were recommended to hospital for pre-pregnancy health examination, which is provided by the government for free of charge. Any couples applied for pre-pregnancy health examination were asked to participate this study. Once obtained agreement, our trained staff will facilitate them to fill in the questionnaire. The hard copy of questionnaires was double-entered into Excel (Microsoft) spreadsheets, after which an audit was performed for quality assessment to rule out all unqualified, incomplete, or incorrect entries. Data were analyzed using SPSS version 17.0 for Windows (Chicago. IL, USA). Pearson Chi-square test was used to test qualitative associations if all expected frequencies are equal to or greater than 5, Fisher's test would be used when the expected frequencies are less than 5. Mann-Whitney test was used for testing difference between two sets of continuous variables, when with equal variances; and Wilcoxon Rank Sum test was used in heterocedasticity. A P-value of 0.05 or less was used to define statistical significant results.

\section{Results}

We have introduced the questionnaires to 3946 couples and 3,202 pairs agreed to participate, with the response rate of $81.1 \%$. Among them, 1,173 were from Jiangsu and 2,029 were from Hebei, respectively. Then the incomplete or unqualified questionnaires were ruled out, 
2,806 questionnaires (1,011 from Jiangsu and 1,795 from Hebei) were determined to be valid for further analysis.

\section{Women's pregnancy history and outcomes}

Details of women's pregnancy history and outcomes were shown in Table 1. Women are classified as primiparous or multiparous. Although China's "One-child policy" started in 1979, many provinces have updated the policy that allows a couple to have two children if both parents have no sibling after 2005. In Jiangsu province, 435 (43.0\%) participants had a previous history of pregnancy. Of these participants, 287 (28.4\%) had had an abortion (induced); 132 (13.1\%) had had a miscarriage (spontaneous); 8 (1.8\%) had had a stillbirth; and $126(29.0 \%)$ had had a successful delivery, giving birth to 128 infants. Of these 128 infants, 9 were premature, 5 were low in birth weight, and 14 were reported to be affected by birth defects. In Hebei province, 1,004 (55.9\%) participants had a previous history of pregnancy. Of these participants, 273 (15.2\%) had had an abortion; 87 (4.8\%) had had a miscarriage, $19.4 \%$ of which occurred after abortion (medically induced); 28 (10.3\%) had had a still birth; and 826 (82.3\%) had successful deliveries, giving birth to 829 infants. Among these infants, 17 (2.1\%) were premature, $15(1.8 \%)$ were low in birth weight, and $16(1.9 \%)$ were reported to be affected by birth defects.

Statistical significance were identified for the variation in the history of pregnancy, abortion, miscarriage, successful delivery, and also for prematurity and birth defects between two provinces.

\section{General health indicators}

The details of the general life indicators of female participants are shown in Table 1 . The age of female participants were compared with rank sum test. The results show statistical significance $(\mathrm{P}<0.001)$. In Jiangsu province, the female participants' body mass index (BMI) ranged from 15.62 to 38.90 , and the average BMI was 21.01. Most $(79.53 \%, 804 / 1011)$ of these females' BMIs were in the normal range, whereas $14.34 \%(145 / 1011)$ were underweight, $5.74 \%(58 / 1011)$ were overweight (obesity excluded), and $0.4 \%$ (4/1011) were obese (overweight excluded). In Hebei province, the female participants' BMI ranged from 11.67 to 37.78 , and the average BMI was 22.15. Most $(77.83 \%, 1397 / 1795)$ of these females' BMIs were in the normal range, $7.52 \%(135 / 1795)$ were underweight, $13.04 \%(234 / 1795)$ were overweight (obesity excluded), and $1.62 \%(29 / 1795)$ were obese (overweight excluded) [14]. The differences in BMI between the two provinces' participants were assessed with Mann-Whitney test, and the results showed significance ( $\mathrm{u}=13.590, \mathrm{P}<0.001)$.

In Jiangsu province, the height of female participants varied from $140 \mathrm{~cm}$ to $178 \mathrm{~cm}$, and the average height is
$162 \mathrm{~cm}$. In Hebei province, the height of female participants varied from $137 \mathrm{~cm}$ to $178 \mathrm{~cm}$, the average height is $161 \mathrm{~cm}$, and the median height is $160 \mathrm{~cm}$. The differences in height between the two provinces' participants were assessed with Mann-Whitney $U$ test and showed significance $(\mathrm{u}=13.590, \mathrm{P}<0.001)$.

In Jiangsu province, the weights of female participants varied from $40 \mathrm{~kg}$ to $97 \mathrm{~kg}$, with a mean weight of $54.85 \mathrm{~kg}$. In Hebei province, the weights of female participants varied from $31 \mathrm{~kg}$ to $95 \mathrm{~kg}$, with a mean weight of $57.31 \mathrm{~kg}$. Because the weight of the participants were not normally distributed, the Mann-Whitney U test was performed to analyze the differences between the weights for the two provinces. The results show significance $(\mathrm{u}=13.590, \mathrm{P}<0.001)$.

\section{Life related issues}

Relative data were shown in Table 1. Among the participants collected in this study, over $50 \%$ of the participants in Jiangsu have a college degree, but $84.8 \%$ of the participants from Hebei are educated only to the high school level. 38.2\% of Jiangsu's participants are office workers, whereas $63.5 \%$ of Hebei's participants are unemployed.

Living environment of the participants differs. In Jiangsu, most of the participants $(79.72 \%, 806 / 1011)$ live in urban or suburban areas, whereas in Hebei, most participants $(93.70 \%, 1682 / 1795)$ live in rural areas. Less than $50 \%$ of the participants from both provinces are living with their partners alone, for less disturbance from senior relatives. Interestingly, $28.6 \%$ of the participants from Hebei live with four or more relatives. Despite the quality of the rooms in their homes, approximately $80 \%$ of the participants from both provinces have more than one room in their homes per family member.

The questionnaire also covered alcohol, tobacco and illicit drug exposures of women in the past 90 days. Only $7.8 \%$ of Jiangsu participants, and $2.3 \%$ of Hebei participants have taken alcohols in the form of either spirit, wine or beer. Tobacco smoking is less common in the provinces, with $1.2 \%$ and $0.4 \%$ for Jiangsu and Hebei, respectively. The use of illicit drugs is extremely rare: only one case was reported in Jiangsu, and none in Hebei.

\section{Common infectious diseases and chronic diseases}

Chronic diseases (hypertension, anemia, diabetes, periodontitis, hypothyroidism, and heart failure), infectious diseases (sexually transmitted disease, STDs; intestinal parasitic infection), and mental status (history of depression, heavy stress) were assessed in the survey. Anemia and periodontitis were each found in more than $5 \%$ of Jiangsu's participants. In contrast, these diseases were found in $1.03 \%$ and $0.25 \%$ of Hebei participants, respectively. In addition, $1.53 \%$ and $0.25 \%$ of Jiangsu's and 
Table 1 General life indicators and pregnancy history of the female participants

\begin{tabular}{|c|c|c|c|c|c|}
\hline \multirow{3}{*}{ Age, y } & \multicolumn{2}{|c|}{ Jiangsu $(n=1011)$} & \multicolumn{2}{|c|}{ Hebei $(n=1795)$} & \multirow{4}{*}{$\begin{array}{l}\text { Comparison } \\
P<0.001 \text { (Rank Sum) }\end{array}$} \\
\hline & \multicolumn{4}{|c|}{$\mathrm{N}(\%)$ or median (IQR) } & \\
\hline & \multicolumn{2}{|c|}{$28.3(\mathrm{IQR}=4)$} & \multicolumn{2}{|c|}{$27.3(\mathrm{IQR}=6)$} & \\
\hline $15-18$ & 0 & - & 1 & $(0.1 \%)$ & \\
\hline $18-25$ & 239 & $(23.6 \%)$ & 673 & $(37.5 \%)$ & \\
\hline $26-35$ & 733 & $(72.5 \%)$ & 1007 & $(56.1 \%)$ & \\
\hline $36-45$ & 39 & $(3.9 \%)$ & 112 & $(6.2 \%)$ & \\
\hline $45+$ & 0 & - & 2 & $(0.1 \%)$ & \\
\hline \multicolumn{5}{|l|}{ Occupation } & \multirow{12}{*}{$X^{2}=901.78, P<0.001$} \\
\hline Unemployed & 266 & $(26.3 \%)$ & 1140 & $(63.5 \%)$ & \\
\hline IT & 2 & $(0.2 \%)$ & 10 & $(0.6 \%)$ & \\
\hline Sales & 43 & $(4.3 \%)$ & 30 & $(1.7 \%)$ & \\
\hline Office & 386 & (38.2\%) & 65 & $(3.6 \%)$ & \\
\hline Service & 94 & $(9.3 \%)$ & 210 & $(11.7 \%)$ & \\
\hline Labor & 87 & $(8.6 \%)$ & 125 & $(7.0 \%)$ & \\
\hline Medical & 34 & $(3.4 \%)$ & 9 & $(0.5 \%)$ & \\
\hline Teaching & 93 & $(9.2 \%)$ & 34 & $(1.9 \%)$ & \\
\hline Student & 2 & $(0.2 \%)$ & 0 & - & \\
\hline Legal & 4 & $(0.4 \%)$ & 0 & - & \\
\hline Peasant & 0 & & 172 & $(9.6 \%)$ & \\
\hline \multicolumn{5}{|l|}{ Education } & \multirow{6}{*}{$X^{2}=916.33, P<0.001$} \\
\hline Illiteracy & 10 & $(1.0 \%)$ & 4 & $(0.2 \%)$ & \\
\hline Below Primary & 7 & $(0.7 \%)$ & 8 & $(0.4 \%)$ & \\
\hline Primary & 29 & $(2.9 \%)$ & 74 & $(4.1 \%)$ & \\
\hline High school & 318 & (31.5\%) & 1522 & $(84.8 \%)$ & \\
\hline University \& above & 647 & $(64.0 \%)$ & 187 & $(10.4 \%)$ & \\
\hline \multicolumn{5}{|l|}{ Place of living } & \multirow{3}{*}{$X^{2}=1583.2, P<0.001$} \\
\hline Urban & 806 & (79.7\%) & 113 & $(6.7 \%)$ & \\
\hline Rural & 205 & $(20.3 \%)$ & 1682 & $(93.7 \%)$ & \\
\hline \multicolumn{5}{|l|}{ Number of people living with } & \multirow{6}{*}{$X^{2}=110.46, P<0.001$} \\
\hline 1 & 469 & $(46.3 \%)$ & 659 & $(36.7 \%)$ & \\
\hline 2 & 166 & $(16.4 \%)$ & 275 & $(15.3 \%)$ & \\
\hline 3 & 257 & $(25.4 \%)$ & 346 & $(19.3 \%)$ & \\
\hline 4 & 93 & $(9.2 \%)$ & 433 & $(24.1 \%)$ & \\
\hline 5 and more & 26 & $(2.6 \%)$ & 82 & $(4.5 \%)$ & \\
\hline \multicolumn{5}{|c|}{ Number of rooms per person in the house/apartment } & \multirow{4}{*}{$X^{2}=23.17, P<0.001$} \\
\hline 1 and less & 201 & $(19.9 \%)$ & 425 & $(23.7 \%)$ & \\
\hline 2 & 615 & $(60.8 \%)$ & 1140 & $(63.5 \%)$ & \\
\hline 3 and more & 195 & $(19.3 \%)$ & 229 & $(12.8 \%)$ & \\
\hline \multicolumn{6}{|l|}{ Previous pregnancy } \\
\hline History of pregnancy & 435 & $(43.0 \%)$ & 1004 & $(55.9 \%)$ & $X^{2}=16.19, P=0.001$ \\
\hline History of Abortion & 287 & $(28.4 \%)$ & 273 & $(15.2 \%)$ & $X^{2}=70.32, P<0.001$ \\
\hline History of miscarriage & 132 & $(13.1 \%)$ & 87 & $(4.8 \%)$ & $X^{2}=4.3, P=0.038$ \\
\hline History of stillbirth & 8 & $(1.8 \%)$ & 28 & $(10.3 \%)$ & $X^{2}=3.02, P=0.082$ \\
\hline History of successful delivery & 126 & $(29.0 \%)$ & 826 & (82.3\%) & $X^{2}=324.82, P<0.001$ \\
\hline
\end{tabular}


Table 1 General life indicators and pregnancy history of the female participants (Continued)

\begin{tabular}{|c|c|c|c|c|c|}
\hline Infants produced & 128 & & 829 & & \\
\hline Premature & 9 & $(7.0 \%)$ & 17 & $(2.1 \%)$ & $P<0.004$ (Two-tailed) \\
\hline Low birth weight & 5 & $(3.9 \%)$ & 15 & $(1.8 \%)$ & $P=0.171$ (Two-tailed) \\
\hline Birth defects & 14 & (10.9\%) & 16 & $(1.9 \%)$ & $P<0.001$ (Two-tailed) \\
\hline
\end{tabular}

Abortion: induced abortion.

Miscarriage: spontaneous miscarriage.

Hebei participants, respectively, reported that they experience heavy stress in everyday life.

\section{Immunization and supplement intake}

Details of the women's immunization and supplement intake were shown in Table 2. Three common immunizations were included in the survey: measles, mumps, and rubella (MMR); tetanus; and hepatitis B virus (HBV). The numbers of participants who received all three vaccinations are much higher in Jiangsu than in Hebei.

\section{Further needs in preconception health care service}

Table 3 lists the issues in preconception health care which are concerned and required by the couples participated the study. The issues selected most frequently by participants from Jiangsu's were folate and iodized salt supplementation, education on pregnancy health checkups, micronutrient supplementation, environmental risks, birth spacing, STD prevention, and healthy weight maintenance. The topics selected most frequently by Hebei's participants were education on pregnancy health checkups, micronutrient supplementation, environmental risks, and birth spacing. Less than $20 \%$ of the participants from both provinces required improvements in immunization and contraception, and $2.3 \%$ of Jiangsu participants and $4.8 \%$ of Hebei participants selected MMR vaccination as

Table 2 Immunization and micronutrient supplement of the female participants

\begin{tabular}{|c|c|c|c|c|c|}
\hline & \multirow{2}{*}{\multicolumn{2}{|c|}{$\begin{array}{c}\text { Jiangsu } \\
N(\%)\end{array}$}} & \multirow{2}{*}{\multicolumn{2}{|c|}{$\begin{array}{l}\text { Hebei } \\
N(\%)\end{array}$}} & \multirow{3}{*}{$\begin{array}{l}\text { Comparison } \\
\text { Chi-square }\end{array}$} \\
\hline & & & & & \\
\hline \multicolumn{5}{|l|}{ Immunized } & \\
\hline MMR & 894 & $(88.4 \%)$ & 264 & $(14.7 \%)$ & $X^{2}=1450.13, P<0.01$ \\
\hline Tetanus & 341 & $(33.7 \%)$ & 92 & $(5.1 \%)$ & $X^{2}=405.47, P<0.01$ \\
\hline HBV & 616 & $(60.9 \%)$ & 585 & $(32.6 \%)$ & $X^{2}=212.16, P<0.01$ \\
\hline \multicolumn{6}{|c|}{ Taking micronutrient supplement } \\
\hline Folate & 424 & $(41.9 \%)$ & 783 & $(43.6 \%)$ & $X^{2}=0.75, P>0.05$ \\
\hline Iron & 26 & $(2.6 \%)$ & 103 & $(5.7 \%)$ & $X^{2}=14.78, P<0.01$ \\
\hline Calcium & 71 & $(7.0 \%)$ & 202 & $(11.3 \%)$ & $X^{2}=13.18, P<0.01$ \\
\hline Multi-vitamin & 124 & $(12.3 \%)$ & 44 & $(2.5 \%)$ & $X^{2}=110.66, P<0.01$ \\
\hline iodized salt & 815 & $(80.6 \%)$ & 1153 & $(64.2 \%)$ & $X^{2}=82.84, P<0.01$ \\
\hline
\end{tabular}

MMR: measles, mumps and rubella. HBV: hepatitis B virus. an additional requirement in preconception. A major variation in the needs for education on genetic risks was identified between the participants from two provinces. This topic was selected by $23.9 \%$ of Jiangsu's couples and $57 \%$ Hebei's couples.

\section{Discussion}

The surveyed populations were carefully selected for the provinces' characteristic geographical and socioeconomic statuses. Jiangsu province, which is in the Yangtze River Delta Economic Zone neighboring to Shanghai, is the modern region with a well-developed socioeconomic environment that may represent all of the provinces on the east coast of China. Hebei province, a northern region surrounding Beijing but covered in its western area by the Taihang Mountains, most of the regions are still under-developed. The ethnic compositions of the two provinces are very similar, with Han people (majority of the Chinese) weighted over 95\% [15]. The climates of the two provinces are distinct, as the annual average temperature of Jiangsu is $2^{\circ} \mathrm{C}$ higher than that of Hebei, and Jiangsu has an annual rain fall of 704-1250 mm, which is nearly double that of Hebei $[16,17]$.

\section{General health indicators}

In the statistical analysis of the results, many differences in general health indicators and lifestyle were identified between the two groups of participants. Women older than 35 years of age were classified as advanced maternal age and were informed that a longer period may be required to achieve conception and that there would be increased risks of pregnancy complications and chromosomal aberrations for the fetuses. These women were also informed about effective screening methods for the detection of fetal chromosomal aberrations [18]. The participants from Jiangsu were generally older in age than those from Hebei. Considering the occupational construction of two groups of participants, this could conclude that the average reproductive age of the urban population is one year higher than that of the rural population. Participants in both provinces specified the need for enhanced preconception education for healthy maternal age, and for pregnancy management of women of advanced maternal age, especially in Jiangsu province, which has a greater proportion of women with advanced maternal age. 
Table 3 The couples' needs to improve preconception health care

\begin{tabular}{|c|c|c|c|c|c|c|}
\hline \multirow{3}{*}{ Immunization } & \multirow{2}{*}{\multicolumn{2}{|c|}{$\begin{array}{c}\text { Jiangsu } \\
\mathrm{N}(\%)\end{array}$}} & \multirow{2}{*}{\multicolumn{2}{|c|}{$\begin{array}{c}\text { Hebei } \\
N(\%)\end{array}$}} & \multirow[t]{2}{*}{ Rate ratio } & \multirow[t]{2}{*}{$95 \% \mathrm{Cl}$} \\
\hline & & & & & & \\
\hline & & & & & & \\
\hline MMR & 23 & $(2.3 \%)$ & 86 & $(4.8 \%)$ & 0.479 & $0.301-0.747$ \\
\hline Tetanus & 24 & $(2.4 \%)$ & 36 & $(2.0 \%)$ & 1.200 & $0.710-1.973$ \\
\hline HBV & 123 & $(12.2 \%)$ & 326 & $(18.2 \%)$ & 0.670 & $0.553-0.812$ \\
\hline \multicolumn{7}{|l|}{ Supplements } \\
\hline Folate & 805 & (79.6\%) & 943 & (52.5\%) & 1.516 & $1.436-1.600$ \\
\hline Iron & 191 & (18.9\%) & 500 & (27.9\%) & 0.678 & $0.585-0.786$ \\
\hline Calcium & 221 & (21.9\%) & 600 & (33.4\%) & 0.656 & $0.572-0.747$ \\
\hline lodized salt & 535 & (52.9\%) & 799 & $(44.5 \%)$ & 1.189 & $1.100-1.285$ \\
\hline \multicolumn{7}{|l|}{ Knowledge } \\
\hline Birth spacing & 725 & (71.7\%) & 1360 & (75.8\%) & 0.947 & $0.903-0.992$ \\
\hline STD prevention & 551 & (54.5\%) & 1043 & (58.1\%) & 0.938 & 0.875-1.005 \\
\hline Genetic risk & 242 & (23.9\%) & 1024 & $(57.0 \%)$ & 0.420 & $0.373-0.472$ \\
\hline Healthy weight maintenance & 688 & $(68.1 \%)$ & 1271 & $(70.8 \%)$ & 0.961 & 0.913-1.012 \\
\hline Micronutrient supplement & 792 & $(78.3 \%)$ & 1405 & $(78.3 \%)$ & 1.001 & $0.961-1.042$ \\
\hline Environmental risk & 720 & $(71.2 \%)$ & 1392 & $(77.5 \%)$ & 0.918 & 0.877-0.962 \\
\hline Health check-up during pregnancy, when, why, how & 825 & $(81.6 \%)$ & 1407 & $(78.4 \%)$ & 1.044 & $1.004-1.084$ \\
\hline \multicolumn{7}{|l|}{ Other needs } \\
\hline Contraception & 338 & $(33.4 \%)$ & 303 & $(16.9 \%)$ & 1.981 & $1.731-2.266$ \\
\hline
\end{tabular}

BMI is an officially accepted tool to evaluate body fat, and it directly influences the pregnancy. A largescale epidemiological study reported that the overweight (obesity included) rate is higher for the northern China population than for the southern China population [19]. Increased BMI is associated with an increased risk for infertility [20], gestational diabetes, and hypertension [21]. In Hebei, the proportions of the overweight and the obese are higher than in Jiangsu. A higher rate of underweight for Jiangsu participants has been noted. Underweight has been shown to be associated with an increased risk of preterm deliveries, low birth weight, and anemia [22]. Both extremes of maternal BMI showed a strong association with pregnancy complication and perinatal outcomes. Awareness must be raised, and more education and actual activities should be provided to reproductive-age women, addressing healthy weight management for both the underweight and the obese, specifically and respectively.

Education level and occupation reflect individuals' level of knowledge, ability to understand information, and earning power, thus may also link to their economic status. Higher proportions of university graduates with master and doctoral degree and white collar workers were found in Jiangsu's participants. People with more education can understand preconception services better and have greater concern and a more positive attitude about health-related issues [23]. Studies have shown that more highly educated people have greater intention to prepare for/manage their pregnancy scientifically $[18,24,25]$. The lower education level of rural women greatly limits their intention to access preconception service, resulting in less involvement in preconception health care [18]. A study of low-income Mexican Americans suggested that among women of child-bearing age, younger ages were associated with less knowledge [26]. The lower average age of the participants from Hebei may correlate with their lower education level. Improving education level and raising awareness are needed. Instead of treating all patients in a standard, routine fashion, doctors should provide clearer and more detailed explanations for less educated populations.

\section{Status of diseases that may affect pregnancy}

Infectious disease can impact pregnancy-related outcomes and the reproductive health of women. Preconception screening for STDs, including HBV and human immunodeficiency virus (HIV), and hypothyroidism is provided by the Chinese government in the preconception health care package [8]. A benefit of preconception screening for STDs with appropriate treatment was the reduced rate of preterm birth [27]. The prevalence of infectious and most chronic diseases is below $0.5 \%$ for both provinces. The prevalence of anemia and periodontitis both were over 5\% in Jiangsu, and lower in Hebei. 
Untreated anemia before pregnancy may lead to preterm labor, low birth weight [28], fetal growth retardation, and infantile developmental delay [29], and if postpartum hemorrhage occurs, it may cause death. Periodontitis mainly affects the delivery time and elevates the risk of preterm labor [30]. Researches on anemia and periodontitis carried out by other Chinese groups have shown that the prevalence for both diseases is higher in rural regions than in urban areas [31,32]. Our finding in current study illustrated the opposite finding, that the prevalence for both diseases were lower in less developed Hebei Province. Together with the abnormally low prevalence of anemia and periodontitis in this study, the only possible explanation could be that the questionnaires were not filled in by medical professionals with screening instruments in hands but by the couples, and many mild cases were ignored [33]. Thus more preconception educational programs are required to improve the awareness and knowledge on the adverse effects of these common chronic diseases.

A stressful psychological state may lead to miscarriage, preterm delivery, low birth weight, or fetal brain developmental disorders as well as the risk of the baby developing schizophrenia and related disorders in later life [34-36]. During preconception counseling, once a woman is identified with a history of depression, severe psychological stress, or anxiety, she will be referred for psychological counseling to reduce the level of stress, if the facility is available locally. The occurrence of psychological problems among Jiangsu's participants is higher. Some researchers reported that the psychological burden for the urban population is greater than for the rural population [37], and its occurrence increased with higher education level groups [38]. The leading causes of such burden in reproductive-age women are work and family-related issues [39]. Therefore more attention should be drawn to the psychological problems of the urban population not only for preconceptional health but also for normal life quality.

\section{Life style}

For both provinces the alcohol consumption were rarely occurred among female participants, much lower than the data reported by Current Status of Alcohol consumption in China, which found $18.3 \%$ women drunk alcohol more than once in three months [40]. Fetal alcohol syndrome (FAS) is more likely to occur after continuous or heavy intake of alcohol during pregnancy. Effects have also been observed after intermittent or binge drinking during pregnancy $[41,42]$ and even from lower-level alcohol use. Other factors such as timing of exposure, maternal or fetal genetic factors affecting metabolism, or individual susceptibility coupled with other harmful behaviors can all contribute to determining the outcome of an alcohol-exposed pregnancy. The lower limit of alcohol intake at which no adverse effect will occur for any developing fetus has not yet been determined and may not even exist $[42,43]$. Thanks for the vast preconceptional education campaigns for avoiding unhealthy life style before pregnancy, most Chinese women avoid alcohol consumption during pregnancy by their own intention [44], but for certain minor ethnic groups, the potential for alcohol consumption during pregnancy is higher, due to their unique habit and religion [45].

Apart from increased risks of cancer and pulmonary and cardiovascular disease, smoking can also lead to premature birth, sudden infant death, and ectopic pregnancy, and it has implications for the umbilical cord during pregnancy [46]. Since 1987, lung cancer has outpaced breast cancer as the leading cause of cancer death among women in the world, and exposure to environmental tobacco smoke (ETS) is a cause of lung cancer and coronary heart disease among lifelong nonsmokers. Moreover, infants born to women who are exposed to ETS during pregnancy may also have increased health risks, including small decreases in birth weight and slightly increased risk for intrauterine growth retardation, compared with infants born to women who were not exposed. In the U.S., $20 \%$ of women smoked cigarettes in 2003 [47], and $11.4 \%$ of women giving birth reported smoking during their pregnancy [48]. In China, $2.4 \%$ of women smoke, mostly between the ages of 20 and 39 years [49]. In comparison, the tobacco smoke rate were both lower than national average, especially in Hebei province. The preconceptional education campaign is also major driving force for the reduction among these child-bearing age participants.

Alcohol consumption, smoking, and drug consumption have been maintained at a low level from the preconception period; the current strategy appears to be effective in preventing unhealthy life styles that are detrimental to pregnancy health.

\section{Micronutrient supplementation}

The use of five common micronutrients-folate, iron, calcium, multi-vitamins, and iodized salt-was assessed in the survey. All of these micronutrients are beneficial for pregnancy: folate and iodized food can reduce the risk of neural tube defects and hypothyroidism, and iron and calcium are effective for preventing pregnancy anemia and pregnancy osteoporosis. All the supplements are commercially available in both provinces. Apart from folate, the status of supplement intake of iron, calcium, multi-vitamin, and iodized salt in the two groups of participants differed. Hebei participants have more intention to take iron and calcium, whereas Jiangsu participants prefer multi-vitamins and iodized salt. In both provinces, less than $50 \%$ of the women took folic acid, although the 
supplement was provided free of charge by local maternal health clinics. Other studies reported similar findings of low intake rate of the free folic acid [45,50]. The causes of low usage of folic acid are thought to be insufficient knowledge of the effect of micronutrients on healthy pregnancy, partners' attitude, and doctors' guidance, deduced by Liu et al. [50]. Thus, proper education should be provided to both women and their partners to improve the understanding of the important of micronutrient supplementation during preparation for conception and within the gestation, at the same time the service standard of doctors also needs to be ensured.

\section{Immunization}

In this study we monitored immunizations for HBV, Tetanus and MMR. The overall immunization rate for Jiangsu's female participants was greatly higher than the Hebei's. Many vaccine-preventable diseases may have serious consequences for both mother and fetus during pregnancy, which makes the immunization status of women of reproductive age an important focal point for preconception care. The prevalence of HBV infection is high. According to a national survey of China published in 2008, 93 million people were infected by HBV, of which 30 million are patients affected with hepatitis B [51]. There is a $10-90 \%$ possibility of neonatal transmission of HBV [52]. In addition, infants who are exposed to acute infection in utero have a risk of low birth weight and prematurity [53]. Prevention of congenital rubella syndrome is a prototype for preconception care because the vaccination is needed before conception and is very effective in preventing a congenital disease that has significant morbidity and mortality rates. The prevention of rubella normally comes as part of the MMR vaccine, which has been found to be very efficacious for all three viral illnesses [54]. Tetanus is a condition that is caused by the inoculation of Clostridium tetani spores, which are widely distributed throughout the environment. Neonatal infection is extremely rare. There is no evidence that the tetanus toxoids vaccine is teratogenic when used extensively. The rate of immunization with the HBV, MMR, and tetanus vaccines is much higher in Jiangsu than in Hebei. A study of HBV immunization suggested that the immunization rate strongly correlated with awareness [55]; other studies also suggested that familial economic status and level of education also affect the rate of immunization [56]. Therefore, apart from the preconception education for immunization is urgently demanded in Hebei, enhanced guidance system operated by medical professionals is also required.

\section{Further needs reported by participants}

The existing preconception health care network is under the administration of the National Committee of Family
Planning and was originally established for the implementation of the "One-child policy". Contraception assistance used to be its first priority. Preconception health care was introduced to the system after 2000, and the national general guideline for providing preconception health care was issued in 2007 and then renewed in 2011 [8]. Folic acid supplementation, education on environmental and genetic risks to pregnancy, and healthy weight maintenance are included in the guideline. However, the education doctors provide on these topics is usually routine and impersonal, lasting only 10 minutes, if that long-a booklet often substitutes for the whole education, due primarily to the shortage of preconception doctors.

Other topics such as immunization and micronutrient supplementation are generally absent from the preconception education. Patients frequently asked questions about micronutrient supplementation before and during pregnancy, and the doctors' answers varied largely, as no official document was issued for this topic. After the "Population and family planning regulations" changed from 2003 to 2005, and allowed a second child if both sides of the couple have no sibling, questions about birth spacing were asked with increasing frequency. In current study, more than $70 \%$ of the participants from both provinces requested information about birth spacing. Inclusion of information on STD prevention is not mandatory in the service; however, some sites that have set up such education have seen encouraging results [57].

Although vaccination in the preconception period has been shown to have beneficial effects, immunization is excluded from the guideline [58]. No evidence was found that preconception immunization has been implemented on a large scale in China, although suggestions to be immunized before becoming pregnant can be found both on the Internet and printed media released by the Ministry of Health. The U.S. Centers for Disease Control and Prevention issued a list of vaccinations that are recommended in the preconception period, which includes MMR, Tetanus, HBV, influenza, varicella, diphtheria, and human papillomavirus vaccinations [26] and thus must be taken into consideration by the Chinese authorities.

\section{Conclusion}

In summary, the study identified that the two surveyed populations differ in maternal age, BMI, education, immunization status, and common pregnancy affecting disease pattern, as well as the additional demands to the existing preconception service. The results suggest the following. First, the existing preconception health care service is effective on correcting unhealthy life styles. Second, more scientific education and training are required for both reproductive-age women and doctors, to enrich the knowledge of the public and also to ensure the quality of the service provided by the medical professionals. Third, 
regional government should design a local version of the preconception health care service guideline, which could be implemented along with the national one to best fit the physical, psychological, and environmental requirements of the local population. Fourth, distribution of general medical services is unbalanced, with an overconcentration of centers with top service standards in developed areas. The standard of medical services in under-developed areas demands urgent improvement.

\section{Abbreviations}

BMI: Body mass index; STD: Sexually transmitted disease; HBV: Hepatitis B virus; MMR: Measles, mumps, and rubella; ETS: Environmental tobacco smoke.

\section{Competing interests}

The authors declare that they have no competing interests.

\section{Authors' contributions}

$X Z, X J$ and $N Z$ were involved in design and organization of the study. $X J, J Z$, GL, XH, FM, QM, QC and YM contributed in the data collection. XZ, YT and $\mathrm{NZ}$ participated in data analysis and interpretation. $\mathrm{XZ}, \mathrm{CH}$ and $\mathrm{NZ}$ drafted and revised the manuscript. All authors read and approved the final manuscript.

\section{Acknowledgements}

The authors thank all the women and their families participating in this research project. This project is partly supported by the March of Dimes Global Network for Maternal and Infant Health (MOD-GNMIH), the Peking University Center of Medical Genetics (PUCMG), the Jiangsu Provincial Department of Maternal and Children Healthcare, and the New York State Office for People with Developmental Disabilities (NYS OPWDD).

\section{Author details}

${ }^{1}$ Chinese PLA General Hospital/Medical School of Chinese PLA, Beijing, China ${ }^{2}$ Peking University Center of Medical Genetics, Beijing, China. ${ }^{3}$ Jiangsu Provincial Center for Maternal and Children's Health, Nanjing, Jiangsu Province, China. ${ }^{4}$ Hebei Provincial People's Hospital, Shijiazhuang, Hebei Province, China. ${ }^{5}$ The No. 4 Hospital of Shijiazhuang City, Shijiazhuang, Hebei Province, China. ${ }^{6}$ Hebei Institute of Reproductive Science and Technology, Shijiazhuang, Hebei Province, China. ${ }^{7}$ Yangzhou Municipal Maternal and Children's Hospital, Yangzhou, Jiangsu Province, China. ${ }^{8}$ Wuxi Municipal Maternal and Children's Hospital, Wuxi, Jiangsu Province, China. ${ }^{9}$ Lianyungang Municipal Maternal and Children's Hospital, Lianyungang, Jiangsu Province, China. ${ }^{10}$ March of Dimes Global Network for Maternal and Infant's Health, White Plains, NY, USA. ${ }^{11}$ China Foundation of Birth Defect Intervention and Aid, Beijing, China. ${ }^{12}$ Children's Hospital of Shanghai, Jiaotong University, Shanghai, China. ${ }^{13} \mathrm{New}$ York State Institute for Basic Research in Developmental Disabilities, Staten Island, NY, USA.

Received: 10 March 2014 Accepted: 6 October 2014

Published: 3 November 2014

\section{References}

1. Frey KA: Preconception care by the nonobstetrical provider. Mayo Clin Proc 2002, 77:469-473.

2. Moos MK, Cefalo RC: Preconceptional health promotion: a focus for obstetric care. Am J Perinatol 1987, 4:63-67.

3. Jack BW, Culpepper L: Preconception care. Risk reduction and health promotion in preparation for pregnancy. JAMA 1990, 264:1147-1149.

4. Johnson K, Posner SF, Biermann J, Cordero JF, Atrash HK, Parker CS Boulet S, Curtis MG: Recommendations to improve preconception health and health care-United States. A report of the CDC/ATSDR Preconception Care Work Group and the Select Panel on Preconception Care. MMWR Recomm Rep 2006, 55(RR-6):1-23.

5. Wilson RD, Audibert F, Brock JA, Cartier L, Desilets VA, Gagnon A, Johnson JA, Langlois S, Murphy-Kaulbeck L, Okun N, Pastuck M: Genetic considerations for a woman's pre-conception evaluation. J Obstet Gynaecol Can 2011, 33:57-64.

6. Kate L, Assendelft W, Bran T, Groeneveld P, Hirasing R, Huis A, Offringa M, Poortman Y, Schrander-Stumpel C, Steegers E, Stemerding D, VerlooveVanhorick S, Verweij M, Bolhuis P, Ruiz Van Haperen V: Preconception care: a good beginning. Edited by de Visser M. Hague, The Netherlands: Health Council of Netherlands; 2007

7. Christiansen C, Chandra-Mouli V, Ogbaselassie L, Willumsen J, Mason E: Meeting to develop a global consensus on preconception care to reduce maternal and childhood mortality and morbidity. Edited by Mason E. Geneva, Switzerland: World Health Organization; 2012.

8. Qi H, Chang Q, Li L: Guideline for prenatal and antenatal health care. Chinese J Obstet Gynecol 2011, 46:4.

9. Chen G, Song X, Wang H, Chen J, Zheng X: The beneficial effect of preconception care. Chinese J Fam Plann 2006, 11:655-657.

10. Wang Z, Li F, Shi H, Zhang L: Evaluation on the effect of health education in preconceptional clinic on change of couples' unhealthy hobbies. Chinese J Woman Child Health Res 2012, 23:583-586.

11. Yang $H$, Wang $X$ : The effectiveness of preconception healthcare in Zhongshan City. China Health Care Nutr 2012, 22:2244.

12. Tao T: Analisis on body characteristics of man youth in China. Mod Silk Sci Tech 2010, 25:24-26.

13. Zhang Q: Challenge and countermeasure of new medical mode change. Chinese Med Ethics 2011, 24:298-299.

14. Cao B, Wang H, Zhu YJ, Chen MJ: Risk factors and clinical outcomes of nosocomial infections caused by multidrug resistant Pseudomonas aeruginosa. Zhonghua Jie He He Hu Xi Za Zhi 2004, 27:31-35.

15. China National Bureau of Statistic: The Report for the Fifth National Census of People's Republic of China. Edited by China National Bureau of Statistic. Beijing, China: Central Government of China; 2001

16. Orland JR, Engstrom J, Fridey J, Sacher RA, Smith JW, Nass C, Garratty G, Newman B, Smith D, Wang B, Loughlin K, Murphy EL, the HTLV Outcomes Study (HOST): Prevalence and clinical features of HTLV neurologic disease in the HTLV Outcomes Study. Neurology 2003, 61:1588-1594.

17. Cheng BC, Chang WN, Chang CS, Chee CY, Huang CR, Chen JB, Chang CJ, Hung PL, Wang KW, Chang HW, Lu CH: Guillain-Barre syndrome in southern Taiwan: clinical features, prognostic factors and therapeutic outcomes. Eur J Neurol 2003, 10:655-662.

18. Liu X, Yu Z, Li X, Liu S: Analysis on maternal pre-pregnancy care's utilization and its influence factors of China. Chinese Prim Health Care 2012, 26:43-46.

19. Ji Y, Sun J: Geographic and population difference of BMI in Chinese school-age youth. Chinese J Pediatr 2004, 42:328-332.

20. Shi B, Lou Y, Lou X: The analysis of the correlation between female obesity and infertility. Chinese J Birth Health Heredity 2005, 3:105-115.

21. Teng Y, Yan L, Dong W, Lai J: [Effects of pre-pregnancy BMI on blood glucose, blood pressure and weight in pregnancy]. Wei Sheng Yan Jiu 2010, 39(5):570-572.

22. Ehrenberg HM, Dierker L, Milluzzi C, Mercer BM: Low maternal weight, failure to thrive in pregnancy, and adverse pregnancy outcomes. Am J Obstet Gynecol 2003, 189:1726-1730.

23. Yu C, Li X: Two-level logistic modeling analysis on the factors that influence birth in hospitals in poor rural areas of Sichnan Province. J Sichuan University (medical science edition) 2008, 39:1011-1013.

24. Yin T, Li J, Jin W: The analysis of women's intention, behavior and knowledge of nutrient supplementation before and during pregnancy. Mod Prev Med 2002, 5:641-642.

25. Miller EC, Liu N, Wen SW, Walker M: Why do Canadian women fail to achieve optimal pre-conceptional folic acid supplementation? An observational study. J Obstet Gynaecol Can 2011, 33:1116-1123.

26. Coonrod DV, Bruce NC, Malcolm TD, Drachman D, Frey KA: Knowledge and attitudes regarding preconception care in a predominantly lowincome Mexican American population. Am J Obstet Gynecol 2009, 200:686. e681-687.

27. Bánhidy F, Dudás I, Czeizel A: Preconceptional screening of sexually transmitted infections/diseases. Cent Eur J Med 2011, 6:49-57.

28. Guo $Z$, Jiang G, Zhou Y: Anemia during pregnancy and preterm birth and low birth weight: a meta analysis. Suzhou University J Med Sci 2003, 23:373-377.

29. Chen Y, Ren A, Ye R, Zheng J, Li S, Liu J, Hao L, Li Z: The relationship between anemia before and during pregnancy and neonatal physical development. Maternal Child Health Care China 2009, 24:399-403.

30. Shanthi V, Vanka A, Bhambal A, Saxena V, Saxena S, Kumar SS: Association of pregnant women periodontal status to preterm and low-birth weight babies: a systematic and evidence-based review. Dent Res J (Isfahan) 2012, 9:368-380 
31. Piao J, Lai J, Yin S, Xu Q, Yang X: Study on the anemia status of Chinese population. Acta Nutrimenta Sinica 2005, 27:268-271

32. Lin T, Lu Y, Chen C, Feng Y, Su B, Ding L, Li W, Zhao A: The survey and analysis of peiodontitis in the elders of Bujian Province. Chin J Gerontol 2006, 26:168-169.

33. Wang $H$, Yang $X$, Liii $Y, Y u H$, Fei X: The application of standardized patients in rural doctors professional training. China Health Ind 2011, 34:129-130.

34. Diego MA, Jones NA, Field T, Hernandez-Reif M, Schanberg S, Kuhn C, Gonzalez-Garcia A: Maternal psychological distress, prenatal cortisol, and fetal weight. Psychosom Med 2006, 68:747-753.

35. Lu J: The study of pregnant women and intervention. Mod Rehabil 2000, 3:437-438.

36. Glynn LM, Schetter CD, Hobel CJ, Sandman CA: Pattern of perceived stress and anxiety in pregnancy predicts preterm birth. Health Psychol 2008, 27:43-51.

37. Zhang S, Jiang C, Wang P, Liu M, Liu H, Yu C, Fu Z, Yu Q, Yang X, Na J, Li N, Yan T, Pan G: Epidemiological survey of mood disorders among urban and rural residents in Liaoning Province. Chinese J Prev Cont Chronic Non-Communicable Dis 2008, 16:378-381.

38. $X u$ Y, Ji Y, Yuan Y, Li C, Chang C: Depressive symptoms and related factors among floating population. Chin Ment Health J 2012, 26:112-117.

39. Zhang J, Hao J, Tao F, Wang H, Zhu P, Xu S, Su P: Influencing factors of pregnancy-related anxiety in first trimester of pregnancy. Chinese J Public Health 2011, 27:969-971.

40. Su Z, Hao W, Shen H: Alcohol patterns, alcohol consumption and alcohol-related problems in five areas in China: 2. Health status of drinkers. Chin Ment Health J 2003, 8(17):540-543.

41. Rimmer $C$, de Costa $C$ : A retrospective review of self-reported alcohol intake among women attending for antenatal care in Far North Queensland. Aust N Z J Obstet Gynaecol 2006, 46:229-233.

42. Sood B, Delaney-Black V, Covington C, Nordstrom-Klee B, Ager J, Templin T, Janisse J, Martier S, Sokol RJ: Prenatal alcohol exposure and childhood behavior at age 6 to 7 years: I. dose-response effect. Pediatrics 2001, 108:E34.

43. Ismail D, Gebert R, Vuillermin PJ, Fraser L, McDonnell CM, Donath SM, Cameron FJ: Social consumption of alcohol in adolescents with Type 1 diabetes is associated with increased glucose lability, but not hypoglycaemia. Diabet Med 2006, 23:830-833.

44. Yao Y: The evaluation on the effectiveness of pregnancy health eduction. Chinese J Pract Nurs 2012, 28:93-94.

45. Sun J, Tur S, Lu Y, Wang X, Ma M: Investigation on dietary structure in 318 Uigur pregnant women in Urumchi, Yining and Atushi. Chinese J Clin Rehabil 2006, 10:22-24.

46. Van Nguyen JM, Abenhaim HA: Sudden infant death syndrome: review for the obstetric care provider. Am J Perinatol 2013, 30(9):703-714.

47. Centers for Disease Control and Prevention (CDC): Annual smokingattributable mortality, years of potential life lost, and productivity losses-United States, 1997-2001. MMWR Morb Mortal Wkly Rep 2005 54:625-628.

48. Centers for Disease Control and Prevention (CDC): Cigarette smoking among adults-United States, 2003. MMWR Morb Mortal Wkly Rep 2005, 54:509-513.

49. World Health Organization: WHO Report on the Global Tobacco Epidemic, 2011: Warning About the Dangers of Tobacco. Geneva, Switzerland: Who Health Organization; 2011.

50. Liu P, Bai Y, Hu X, Liu L, Du W: The statistical analysis of the factors influencing the intake of folic acid supplement in pregnant women. Chinese J Health Stat 2012, 29:113-114.

51. Zhuang $\mathrm{H}$ : Current status and goals of hepatitis $\mathrm{B}$ prevention and treatment. Chinese J Intern Med 2008, 47:793-795.

52. American College of Obstetricians and Gynecologists (ACOG): ACOG Practice Bulletin No. 86: Viral hepatitis in pregnancy. Obstet Gynecol 2007, 110(4):941-956.

53. Hieber JP, Dalton D, Shorey J, Combes B: Hepatitis and pregnancy. J Pediatr 1977, 91:545-549.

54. Watson JC, Hadler SC, Dykewicz CA, Reef S, Phillips L: Measles, mumps, and rubella-vaccine use and strategies for elimination of measles, rubella, and congenital rubella syndrome and control of mumps: recommendations of the Advisory Committee on Immunization Practices (ACIP). MMWR Recomm Rep 1998, 47:1-57.
55. Ge F, Ye R, Xie L, Li X, Huang C, Ye D: Investigation on cognition about hepatitis $B$ and inoculation rate of hepatitis B vaccine in Chaohu city. Chinese J Public Health 2008, 24:258-260.

56. Zhou Y, Zheng J, Yang Y, Zheng Q, Zhang D: Investigation of hepatitis B immunization coverage rate and its influential factors in Fujian Province. Chinese J Vaccines Immunization 2000, 6:129-131.

57. Gui X, Zhang H: Effect of short-term health education on STD/AIDS control amoung premarital youngsters, pregnant women and infants' parents in Liuzhou, Guangxi. Chinese J Health Educ 2001, 17:523-526.

58. Xie $Y$ : The investigation of antibody in 156 six-month age babies whose mother had been vaccinated the measles. Chinese J Pest Control 2008, 24:258-259.

doi:10.1186/1471-2393-14-360

Cite this article as: Zhao et al:: Factors influencing the quality of preconception healthcare in China: applying a preconceptional instrument to assess healthcare needs. BMC Pregnancy and Childbirth 2014 14:360

\section{Submit your next manuscript to BioMed Central and take full advantage of:}

- Convenient online submission

- Thorough peer review

- No space constraints or color figure charges

- Immediate publication on acceptance

- Inclusion in PubMed, CAS, Scopus and Google Scholar

- Research which is freely available for redistribution 